\title{
Rapid growth and properties of large-aperture 98\%-deuterated DKDP crystals
}

\author{
Xumin Cai ${ }^{1,2}$, Xiuqing $\mathrm{Lin}^{1}$, Guohui $\mathrm{Li}^{1}$, Junye $\mathrm{Lu}^{1}$, Ziyu $\mathrm{Hu}^{1,3}$, and Guozong Zheng ${ }^{1}$ \\ ${ }^{1}$ Fujian Institute of Research on the Structure of Matter, Chinese Academy of Sciences, Fuzhou 350002, China \\ ${ }^{2}$ University of Chinese Academy of Sciences, Beijing 100049, China \\ ${ }^{3}$ College of Chemistry, Fuzhou University, Fuzhou 350116, China \\ (Received 12 March 2019; revised 22 April 2019; accepted 21 May 2019)
}

\begin{abstract}
In this paper, a highly deuterated potassium dihydrogen phosphate (DKDP) crystal with sizes up to $318 \mathrm{~mm} \times 312 \mathrm{~mm} \times$ $265 \mathrm{~mm}$ was grown by the rapid-growth method. The synthesis tank device was specially designed to synthesize a higher deuterium concentration and high-purity DKDP solution. The deuterium content of the as-grown crystal, which was 97.9\%, was determined by two methods, including infrared (IR) spectroscopy and thermo-gravimetric analysis (TGA) measurements. The performances of the $97.9 \%$ DKDP crystal, including transmission, absorption coefficient, and laserinduced damage threshold (LIDT) were measured. The results indicate that, in the near-infrared band, the transmission of the $97.9 \%$ DKDP crystal is higher than that of KDP and 70\% DKDP crystals, and the absorption coefficient is lower. The LIDT of the crystal reached $23.2 \mathrm{~J} \cdot \mathrm{cm}^{-2}$ (R-on-1, $1064 \mathrm{~nm}, 3 \mathrm{~ns}$ ), which meets the engineering requirements for use in optical applications.
\end{abstract}

Keywords: DKDP crystal; large aperture; highly deuterated DKDP; rapid growth

\section{Introduction}

Deuterated potassium dihydrogen phosphate (DKDP) crystals are optical materials with excellent properties, such as high transmittance, high electro-optic coefficient and high laser damage threshold, which are widely used for frequency conversion and as electro-optical $Q$-switching crystals in inertial confinement fusion (ICF) projects ${ }^{[1-3]}$. In particular, DKDP crystals can grow to very large apertures, up to $900 \mathrm{~mm}$ by the water solution method ${ }^{[2]}$. Due to a hydrogen atom being replaced by a deuterium atom, DKDP crystals have a few differences in performance compared with potassium dihydrogen phosphate (KDP) crystals, including a weak stimulated Raman scattering (SRS) effect ${ }^{[4-6]}$ and a low half-wave control voltage, which is about half that of $\mathrm{KDP}$ crystals $^{[7]}$. As the number of deuterium atoms increases, the electro-optic properties become better ${ }^{[8]}$. The ICF project chooses large-aperture, highly deuterated DKDP crystals as electro-optic switch materials ${ }^{[9]}$. However, the growth of large-size, 98\%-deuterated DKDP crystals faces many difficulties, such as disturbance of the monoclinic DKDP crystal during the growth of the tetragonal DKDP

Correspondence to: G. Zheng, 155 West Yangqiao Road, Fuzhou 350002, China. Email: zhengguozong@fjirsm.ac.cn crystal, hydrogen-deuterium exchange, and the need for expensive heavy water ${ }^{[8,10]}$. To date, there have been very few reports on the growth of highly deuterated DKDP crystals.

The traditional temperature-reduction method for producing crystals has been widely used to grow large-size, highly deuterated DKDP crystals, which requires a long period of more than one year ${ }^{[2,11,12]}$. It is difficult to supply enough DKDP crystals by the traditional method, so a rapid-growth technology is being urgently studied for highly deuterated DKDP crystals. In 2014, Zhang et al. ${ }^{[8]}$ reported that DKDP crystals with a deuterium content of $98 \%$ and sizes of $100 \mathrm{~mm} \times 105 \mathrm{~mm} \times 96 \mathrm{~mm}$ were successfully grown by point-seed technology. The tetragonalto-monoclinic solubility transition can be avoided by the rapid-growth technique ${ }^{[10]}$. It is essential that a rapid-growth method is used for the growth of highly deuterated DKDP crystals by the point-seed technique. The growth of largesize, highly deuterated DKDP crystals is affected by many factors ${ }^{[10,13]}$, such as the need for highly pure raw materials, supersaturation stability, ultrafine filtration, the rate of hydrogen-deuterium exchange, and the disturbance of the monoclinic crystal. At present, large-scale, high-quality, highly deuterated DKDP crystals are urgently needed for 
Table 1. Concentration of the main metallic ionic impurities in $\mathrm{P}_{2} \mathrm{O}_{5}$ raw material (ppb, parts per billion).

\begin{tabular}{cccc}
\hline Element & Concentration $(\mathrm{ppb})$ & Element & Concentration $(\mathrm{ppb})$ \\
\hline $\mathrm{Al}$ & 46.81 & $\mathrm{~Pb}$ & 9.02 \\
$\mathrm{As}$ & 32.74 & $\mathrm{Li}$ & 10.11 \\
$\mathrm{Ba}$ & 13.62 & $\mathrm{Mg}$ & 99.08 \\
$\mathrm{Co}$ & 2.87 & $\mathrm{Mn}$ & 8.32 \\
$\mathrm{Cr}$ & 10.93 & $\mathrm{Ni}$ & 7.51 \\
$\mathrm{Cu}$ & 13.06 & $\mathrm{Sr}$ & 3.84 \\
$\mathrm{Fe}$ & 100.82 & $\mathrm{Zn}$ & 25.19 \\
\hline
\end{tabular}

Table 2. Concentration of the main metallic ionic impurities in $\mathrm{K}_{2} \mathrm{CO}_{3}$ raw material (ppb, parts per billion).

\begin{tabular}{cccc}
\hline Element & Concentration $(\mathrm{ppb})$ & Element & Concentration $(\mathrm{ppb})$ \\
\hline $\mathrm{Al}$ & 123.52 & $\mathrm{~Pb}$ & 18.83 \\
$\mathrm{As}$ & 34.98 & $\mathrm{Li}$ & 39.56 \\
$\mathrm{Ba}$ & 38.12 & $\mathrm{Mg}$ & 172.84 \\
$\mathrm{Co}$ & 10.36 & $\mathrm{Mn}$ & 99.75 \\
$\mathrm{Cr}$ & 55.46 & $\mathrm{Ni}$ & 40.88 \\
$\mathrm{Cu}$ & 39.65 & $\mathrm{Sr}$ & 20.71 \\
$\mathrm{Fe}$ & 546.12 & $\mathrm{Zn}$ & 118.23 \\
\hline
\end{tabular}

ICF projects, and researchers are seeking to make a breakthrough. In this paper, we designed a synthesis tank device to prepare a high-deuterium content DKDP crystal solution. A highly deuterated DKDP crystal was grown rapidly by the point-seed technique and continuous filtration, with a size of more than $300 \mathrm{~mm}$, and the crystal quality was examined.

\section{Experiment}

\subsection{Synthesis}

Synthesis of the growth solution is the most important factor for the growth of highly deuterated DKDP crystals. The usual procedure was adopted to synthesize the highdeuterium concentration growth solution, which was divided into two steps. First, a phosphorus pentoxide $\left(\mathrm{P}_{2} \mathrm{O}_{5}\right)$ reagent of electronic grade $(99.9995 \%)$ reacted with heavy water of isotopic purity (99.8\%). Then, the deuterated ortho-phosphoric acid obtained in the first step reacted with spectrum-pure grade (purity of $99.999 \%$ ) potassium carbonate $\left(\mathrm{K}_{2} \mathrm{CO}_{3}\right)$. The concentrations of the main metallic ionic impurities in the raw materials are listed in Tables 1 and 2. The results in Tables 1 and 2 show that the ingredients are with high purity and can be used for the preparation of the DKDP solution. The reactions are as follows:

$$
\begin{aligned}
& \mathrm{P}_{2} \mathrm{O}_{5}+3 \mathrm{D}_{2} \mathrm{O} \rightarrow 2 \mathrm{D}_{3} \mathrm{PO}_{4}, \\
& 2 \mathrm{D}_{3} \mathrm{PO}_{4}+\mathrm{K}_{2} \mathrm{CO}_{3}+\mathrm{D}_{2} \mathrm{O} \\
& \quad \rightarrow 2 \mathrm{KD}_{2} \mathrm{PO}_{4}+2 \mathrm{D}_{2} \mathrm{O}+\mathrm{CO}_{2} \uparrow .
\end{aligned}
$$

To avoid hydrogen-deuterium exchange, a synthesis tank device was designed to provide a closed environment for

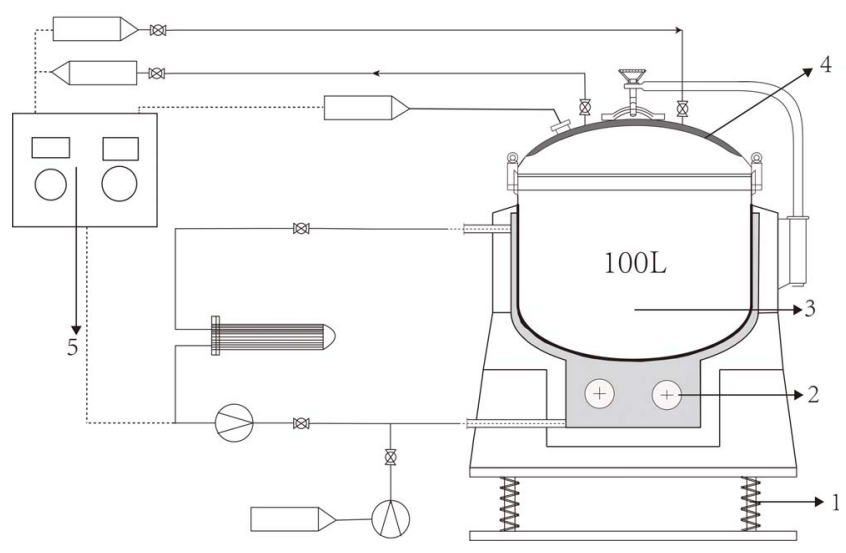

Figure 1. Schematic of the $100 \mathrm{~L}$ synthesis tank device. 1, vibrating table; 2 , heating unit; 3 , synthesis container; 4 , cooling system; 5, control system.

these two reactions. The schematic of the synthesis tank device is shown in Figure 1. It includes the synthesis container, a cooling system, a control system and a heating unit, and synthesizes large batches (volume of $100 \mathrm{~L}$ ) of the growth solution with high purity. The device features highly automated continuous production and high accuracy, and is simple to use compared with the conventional synthesis device.

Before the reactions, $\mathrm{K}_{2} \mathrm{CO}_{3}$ was dried at $105^{\circ} \mathrm{C}$ for more than $12 \mathrm{~h}$ to desiccate and reduce the deuterium loss. During the reactions, the tank was placed in a dry environment with a humidity of less than $20 \%$. The saturated temperature of the solution was controlled to $47^{\circ} \mathrm{C}$ and the $\mathrm{pD}$ value (deuterium ion concentration, $\mathrm{pD}$ is similar to $\mathrm{pH}$ ) was adjusted to 3.9 by calculating the quantity of the raw materials. After the process, the synthesized solution was filtered through a $0.1 \mu \mathrm{m}$ pump and transferred to the crystallizer.

\subsection{Crystal growth}

The solution was overheated for more than $72 \mathrm{~h}$ in the 500-L standard hold-type crystallizer to avoid spontaneous nucleation. The highly deuterated DKDP crystal was grown rapidly from a $12 \mathrm{~mm} \times 12 \mathrm{~mm} \times 6 \mathrm{~mm} z$-cut point seed in the 500-L crystallizer with a continuous filtration system and a temperature control of $\pm 0.1^{\circ} \mathrm{C}$. The seed, which was free of any visible macroscopic defects, was overheated at $52{ }^{\circ} \mathrm{C}$ for $1 \mathrm{~h}$ in the growth solution before growth. During the DKDP crystal growth process, the solution was stable without spontaneous nucleation as the temperature decreased from 47 to $38^{\circ} \mathrm{C}$ and a rotation rate for the platform was adopted with a speed of about $30 \mathrm{r} / \mathrm{min}$.

The as-grown crystal was $318 \mathrm{~mm} \times 313 \mathrm{~mm} \times 265 \mathrm{~mm}$ in size without significant macroscopic defects, with an average growth rate of about $6 \mathrm{~mm} \cdot$ day $^{-1}$, as shown in Figure 2 . 


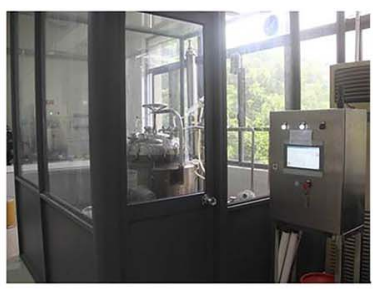

Synthesis tank device

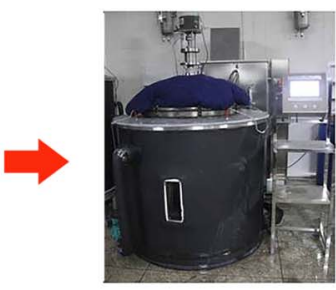

Crystallizer
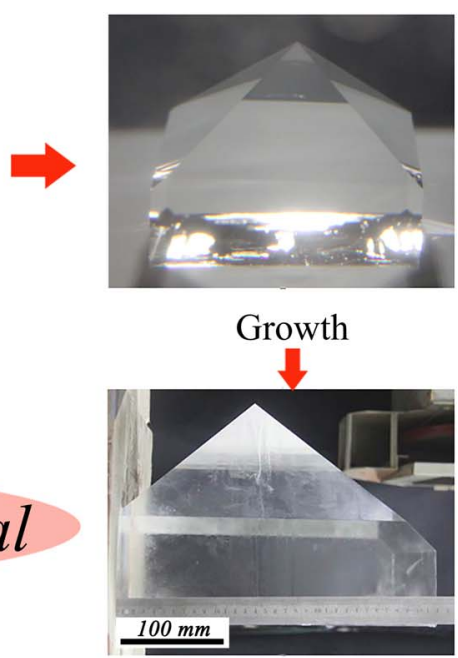

$318 \mathrm{~mm} \times 313 \mathrm{~mm} \times 265 \mathrm{~mm}$

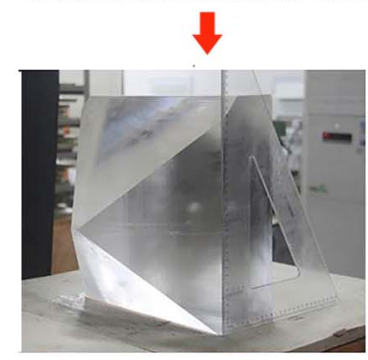

Cutting

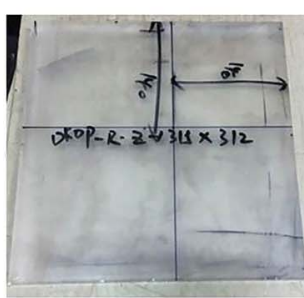

Crystal wafer

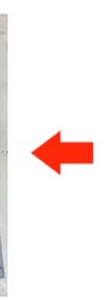

Annealing

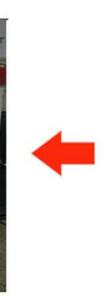

\begin{abstract}
Figure 2. Details of the DKDP crystal producti
\end{abstract}
.

After X-ray orientation and $z$-cut, a $315 \mathrm{~mm} \times 312 \mathrm{~mm} \times$ $12 \mathrm{~mm}$ DKDP crystal wafer was obtained, which was annealed at $120^{\circ} \mathrm{C}$ for $24 \mathrm{~h}$ and used to provide switching devices for the performance examination. Details of the DKDP crystal production process are shown in Figure 2.

\subsection{Measurements}

Transmittance spectra of the crystal were recorded by a Lambda 950 ultraviolet-visible-near-infrared (UV-visNIR) spectrophotometer in the range 200-2000 nm. The spectral resolution of the spectrophotometer was $1 \mathrm{~nm}$. The transmittance value was converted into the absorption coefficient according to the Lambert-Beer law.

The laser-induced damage threshold (LIDT) of DKDP crystals was measured by the Shanghai Institute of Optics and Fine Mechanics. The experimental setup for assessing the damage threshold is shown in Figure 3. The damage threshold was measured by the R-on- 1 test. The test wavelength was $1064 \mathrm{~nm}$ with a pulse length of $8.8 \mathrm{~ns}$ and a $1 \omega$ conversion efficiency. For the sake of engineering applications, test results at $8.8 \mathrm{~ns}$ were eventually normalized to $3 \mathrm{~ns}$.

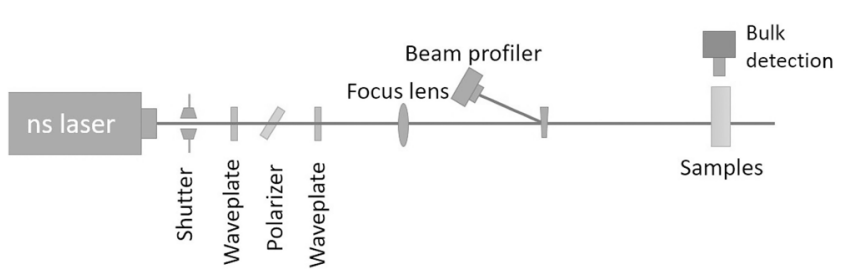

Figure 3. Experimental setup for measuring the LIDT, including shutter, waveplate, polarizer, focus lens, beam profiler and bulk detection.

\section{Results and discussion}

\subsection{Deuterium content of the grown crystal}

In DKDP crystals, especially high-deuterium crystal, an accurate measurement of the deuterium concentration is very important. The chemical and physical properties of the hydrogen and deuterium atoms in the DKDP crystal, such as the structural dimensions, bond lengths and bond angles, are closely related to the deuterium content of DKDP crystals ${ }^{[14,15]}$. There are multiple methods available to determine the deuterium level. These methods depend on different principles to measure the deuterium concentration $^{[16-20]}$, such as the variation in the ferroelectric 
Table 3. Results for the deuterium level of DKDP crystal as assessed from IR spectra.

\begin{tabular}{cccccc}
\hline No. & 1 & 2 & 3 & 4 & Average \\
\hline Deuterium level (\%) & 97.7 & 98.0 & 97.9 & 98.0 & 97.9 \\
\hline
\end{tabular}

\section{transition}

temperature of DKDP, the relationship between the deuterium concentration and the Raman shift of the $\mathrm{PO}_{4}$ vibration peak, the sensitivity of neutrons to hydrogen and deuterium elements, differences in the infrared spectra of hydrogen and deuterium atoms, and the thermo-decomposition of DKDP and KDP crystals, as described in the present literature concerned. These methods have both advantages and drawbacks.

Liu et $a l .{ }^{[21]}$ concluded that infrared (IR) spectra present more accurate values for high-deuterium content DKDP crystals. Li et al. ${ }^{[20]}$ concluded that thermo-gravimetric apparatus (TGA) measurement is an accurate method because the residual mass, which is the weight ratio of $\mathrm{KPO}_{3}$ against DKDP samples, can be obtained from the TG curve of the sample accurately using thermo-gravimetric apparatus. The TGA method has the advantages of simple manipulation, low sample consumption (30-90 mg) and a short measurement period (about $2.5 \mathrm{~h}$ ). Therefore, we used IR spectroscopy and TGA measurements to determine the deuterium content of the as-grown DKDP crystal in this study.

The as-grown DKDP crystal was $z$-cut to obtain samples with sizes of $10 \mathrm{~mm} \times 10 \mathrm{~mm} \times 20 \mathrm{~mm}$. These samples were obtained from prismatic and pyramid regions of the crystal, with the location of the samples shown in Figure 4 . The samples were then lapped and polished without any coating. The IR spectra were measured in the range $200-1800 \mathrm{~nm}$ for $20 \mathrm{~mm}$ thick $z$-cut specimens. The recorded spectra are shown in Figure 5. Based on years of experimental results, a database has been established for the deuterium level and the optical transmission (@1550 nm). This database is constantly revised based on theory (Fresnel losses) and experiments, and the results of the database are reliable. Using this database, the transmission (@1550 nm) can be converted into the deuteration levels which are shown in Table 3. From Table 3, the deuterium concentrations of samples 2 and 4 are a little higher than those of samples 1 and 3. However, the difference is not significant, thus showing excellent homogeneity in the deuterium level. The average value of the deuterium content is $97.9 \%$.

To accurately measure the degree of deuteration of crystals, we also used the TGA method to determine the deuterium concentration of the as-grown DKDP crystal. Samples of approximately $80 \mathrm{mg}$ from different parts of the as-grown DKDP crystal were selected for measurement of the thermo-gravimetric curve. Samples 1 and 2 were taken from the pyramid and prismatic regions of the crystal, respectively, with the location of each sample being shown in Figure 6.

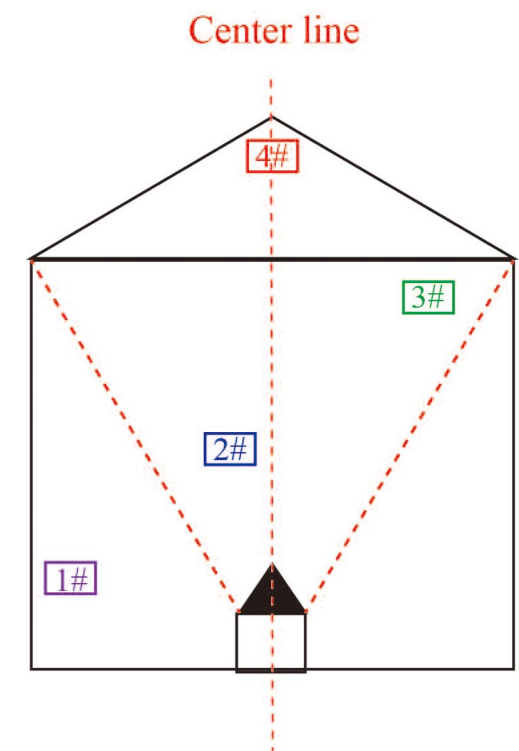

Figure 4. Locations of the samples used in infrared (IR) spectra measurements.

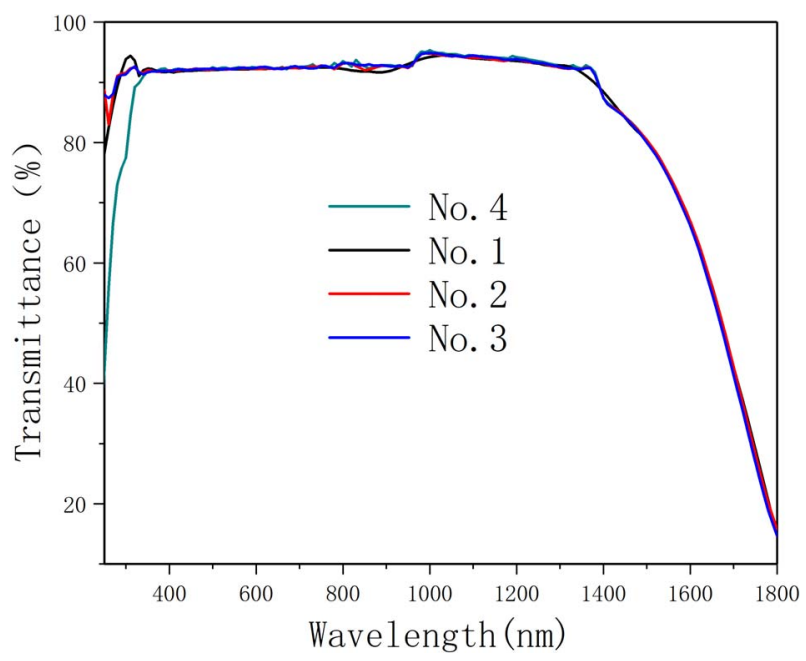

Figure 5. IR spectra. The recorded spectra were measured by a spectrophotometer in the range $200-1800 \mathrm{~nm}$.

The TG curves of the DKDP crystals are shown in Figure 7. The results for the residual weight of DKDP crystals are listed in Table 4. Equation (3) was used to calculate the deuterium concentration of the DKDP crystals, as follows ${ }^{[20]}$ :

$$
D=\left(\frac{58.699}{\alpha}-67.62\right) \times 100 \%
$$

where $D$ is the deuterium level of the DKDP crystal and $\alpha$ is the residual mass. The average value for the degree of deuteration of crystals is $96.94 \%$ by the TGA method. The deuterium level of sample 1 from the pyramid region is a little higher than that of sample 2 from the prism region. The 


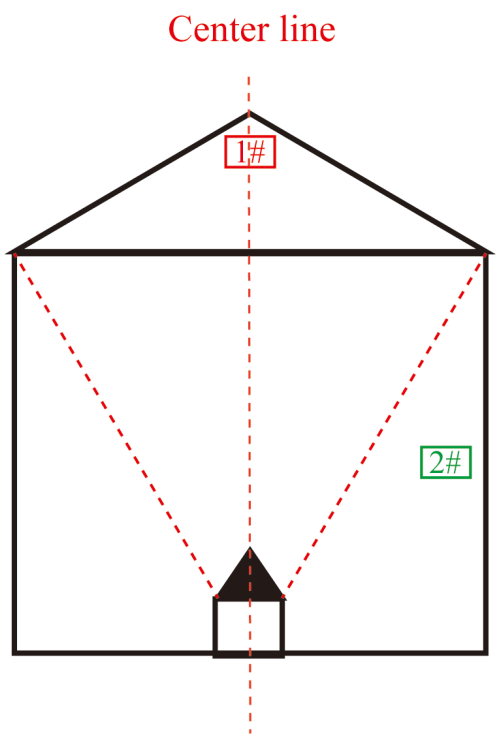

Figure 6. Locations of the samples used in TGA measurements.

deuterium concentration of the pyramid region is higher than that of the prismatic region, but the difference is not obvious. From the results for the deuterium level assessed both by IR spectroscopy and TGA measurements, it is clear that the asgrown crystal possesses good homogeneity in its deuterium concentration. The results obtained from IR spectroscopy are slightly higher than those from TGA measurements. IR spectroscopy is more suitable for measuring highly deuterated DKDP crystals - therefore, the value of $97.9 \%$ measured by IR spectroscopy is used as the measured value of the deuteration level of the as-grown DKDP crystal.

The effective distribution coefficient of deuterium is described by the following exponential equation ${ }^{[17]}$ :

$$
k_{\text {eff }}=0.68 \exp (0.00382 M)
$$

where $M$ is the mole fraction of deuterium in the solution and $k_{\text {eff }}$ is the effective distribution coefficient of deuterium. The deuterium concentration of the mother solution is about 99\%. Hence, the deuterium level of the as-grown crystal is about $98 \%$ according to the exponential equation. Two methods were used to determine the deuterium content of the as-grown DKDP crystals: IR spectroscopy and TGA measurements of the deuterium concentration give $97.9 \%$ and $96.9 \%$, respectively, which are lower than the value calculated by the exponential equation. Because of the effect of hydrogen-deuterium exchange, the deuterium concentration of the solution decreased during the growth of the DKDP crystal. However, in this experiment, it can be ascertained that the deuterium level of the as-grown DKDP crystal was more than $96 \%$ with both measuring methods, and the asgrown crystal is a highly deuterated DKDP crystal as used in the optical components.

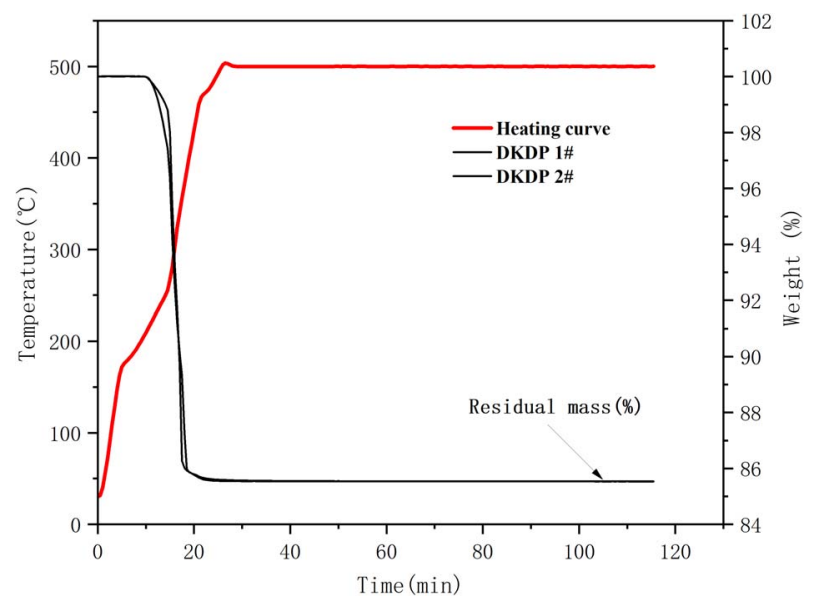

Figure 7. Thermo-gravimetric curve of DKDP crystals. The red curve represents the heating curve and the two black curves represent the TG curve of DKDP.

Table 4. Results of the residual mass and deuterium level of DKDP.

\begin{tabular}{ccc}
\hline Samples & Residual mass (\%) & Deuterium level (\%) \\
\hline DKDP-1\# & 85.53191 & 97.22 \\
DKDP-2\# & 85.53906 & 96.65 \\
Average & 85.53549 & 96.94 \\
\hline
\end{tabular}

\subsection{Optical properties of DKDP crystal}

Highly deuterated DKDP crystals with excellent optical properties are widely used for optical applications. The absorption coefficient of DKDP crystals is a significant parameter used to assess the optical properties and quality of crystals, which was measured from the transmission spectra in this paper. Samples of $15 \mathrm{~mm} \times 15 \mathrm{~mm}$ were $z$-cut from the pyramid region of the large DKDP crystal (the schematic cutting diagram is shown in Figure 8). The samples were processed into plates of $10 \mathrm{~mm}$ thickness and the transmitting faces of the crystal were fine polished without coating by a fly-cutting machine tool until they were free of scratches and the sample became transparent. Optical transmission spectra recorded by a spectrophotometer (Lambda 950) in the range 200-2000 nm at room temperature are shown in Figure 9. We also measured the transmission spectra of 70\% DKDP and KDP crystals under the same conditions.

The highly deuterated DKDP crystal was used in electrooptical $Q$-switch materials for the near-infrared waveband (such as at $1053 \mathrm{~nm}$ or $1064 \mathrm{~nm}$ ). It is observed from Figure 9 that, in the near-infrared band, the transmittance of $97.9 \%$ deuterated DKDP crystal is significantly higher than those of $70 \%$ DKDP and KDP crystals because the introduction and concentration of deuterium atoms weakened the infrared absorption caused by vibrations of the O-H band. Reference [22] considered the transmittance of the crystal at $355 \mathrm{~nm}$ was more than $88 \%$, which indicated that the optical performance of the as-grown 


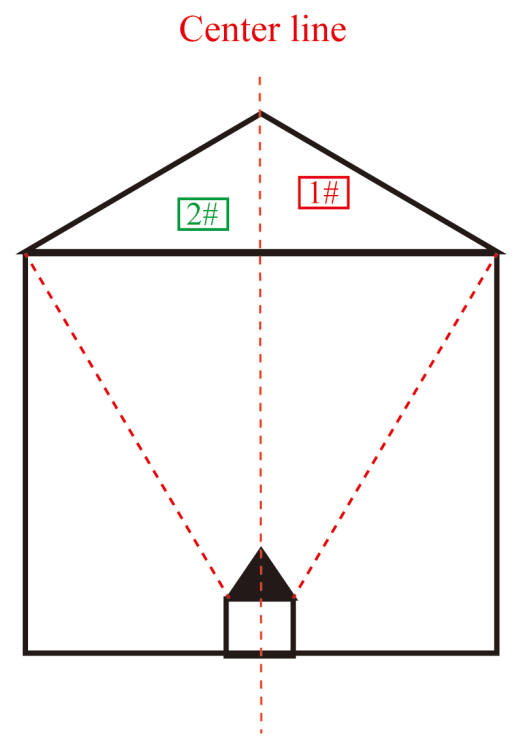

Figure 8. Schematic cutting diagram for the different DKDP samples.

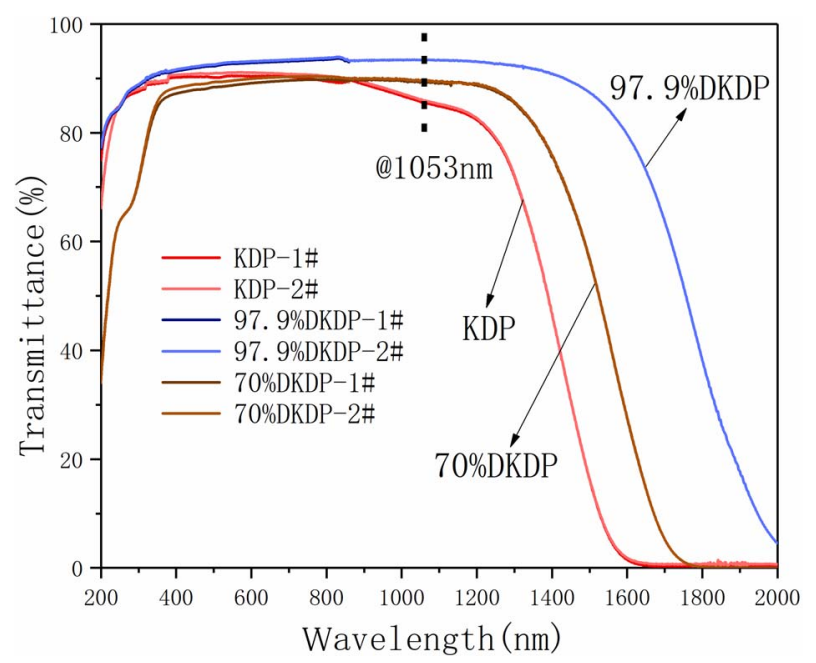

Figure 9. Transmission spectra of different deuterium concentration DKDP and DKP crystals. The blue curve represents $97.9 \%$ DKDP crystal, the brown curve represents $70 \%$ DKDP and the red curve represents KDP crystal.

crystal was pretty good. In Figure 9, the transmittance of all $97.9 \%$ DKDP sample crystals at $355 \mathrm{~nm}$ was more than $89 \%$. The difference in transmission is small between different samples of $97.9 \%$ DKDP crystal, thus indicating the good homogeneity in transmission of the pyramidal crystal. To accurately evaluate the quality of the as-grown crystal, we entrusted Nuclear Physics and Chemistry, China Academy of Engineering Physics to measure the transmittance. They processed the crystal into two $100 \mathrm{~mm} \times$ $100 \mathrm{~mm}$ wafers with a thickness of $10 \mathrm{~mm}$, polished with a
Table 5. Results for the transmittance and absorption coefficient with different deuterium levels in DKDP and KDP crystals.

\begin{tabular}{|c|c|c|c|c|c|c|}
\hline \multirow[t]{2}{*}{ Samples } & \multicolumn{2}{|c|}{ KDP } & \multicolumn{2}{|c|}{$70 \%$ DKDP } & \multicolumn{2}{|c|}{$97.9 \%$ DKDP } \\
\hline & $\begin{array}{c}T \\
(\%)\end{array}$ & $\begin{array}{c}\alpha_{\mathrm{ac}} \\
\left(\mathrm{cm}^{-1}\right)\end{array}$ & $\begin{array}{c}T \\
(\%)\end{array}$ & $\begin{array}{c}\alpha_{\mathrm{ac}} \\
\left(\mathrm{cm}^{-1}\right)\end{array}$ & $\begin{array}{c}T \\
(\%)\end{array}$ & $\begin{array}{c}\alpha_{\mathrm{ac}} \\
\left(\mathrm{cm}^{-1}\right)\end{array}$ \\
\hline $1 \#$ & 85.645 & 0.082 & 89.410 & 0.031 & 93.407 & 0.0052 \\
\hline 2\# & 86.122 & 0.071 & 89.707 & 0.028 & 93.407 & 0.0052 \\
\hline Average & 85.884 & 0.077 & 89.559 & 0.029 & 93.407 & 0.0052 \\
\hline
\end{tabular}

chemical film coating. A spectrophotometer at a wavelength of $1053 \mathrm{~nm}$ was used to measure the transmittance of the samples. The transmittance results were $99.76 \%$ and $99.82 \%$, which are higher than those of samples without any coating at $1053 \mathrm{~nm}$ (Table 5). Therefore, we can conclude that the as-grown highly deuterated DKDP crystal possesses a high transmission.

In accordance with the Lambert-Beer law, the transmittance result is determined by the interface and internal transmittance in the crystal. The relationship can be expressed by the following formula ${ }^{[23]}$ :

$$
T_{\text {meas }}=T_{\text {Fresnel }}+T_{\text {bulk }}+T_{\text {Fresnel }}
$$

where $T_{\text {meas }}$ is the measured transmittance, $T_{\text {Fresnel }}$ is the transmittance of the interface and $T_{\text {bulk }}$ is the internal transmittance in the crystal. As light travels through the crystal, Fresnel reflection occurs at every crystal interface. At the crystal interface, the transmittance $\left(T_{\text {Fresnel }}\right)$ and reflectivity $\left(R_{i}\right)$ have the following relationship:

$$
T_{\text {Fresnel }}=1-R_{i}
$$

$R_{i}$ is estimated from the refractive index, as follows:

$$
R_{i}=\left(\frac{1-n}{1+n}\right)^{2}
$$

In accordance with the Lambert-Beer law,

$$
\begin{aligned}
I_{o} & =I_{i} \mathrm{e}^{-\alpha_{\mathrm{ac} L}}, \\
T_{\text {bulk }} & =\frac{I_{o}}{I_{i}} .
\end{aligned}
$$

Hence, one obtains

$$
T_{\text {bulk }}=I_{i} \mathrm{e}^{-\alpha_{\text {ac } L}} .
$$

Using Equations (5) and (6) directly yields

$$
T_{\text {bulk }}=\frac{T_{\text {meas }}}{\left(T_{\text {Fresnel }}\right)^{2}}=\frac{T_{\text {meas }}}{\left(1-R_{i}\right)^{2}} .
$$




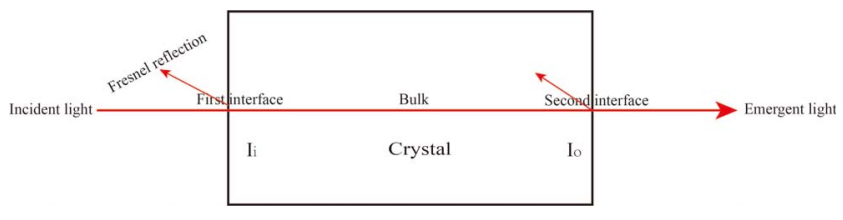

Figure 10. Optical path schematic of the experiment.

Equations (10) and (11) directly yield

$$
\frac{T_{\text {meas }}}{\left(1-R_{i}\right)^{2}}=I_{i} \mathrm{e}^{-\alpha_{\mathrm{ac}} L}
$$

Hence, one obtains

$$
\alpha_{\mathrm{ac}}=\frac{-\ln \left[T_{\mathrm{meas}} /\left(1-R_{i}\right)^{2}\right]}{L},
$$

where $\alpha_{\mathrm{ac}}$ is the absorption coefficient, $R_{i}$ is the reflectivity and $L$ is the thickness of the DKDP sample. $I_{i}$ and $I_{o}$ are the intensities of the incident and emergent light, respectively. $n$ is the refractive index, which is related to the deuterium content of the crystal. A database of the deuterium level and refractive index has been established over many years. The refractive index ( $n$ is approximately 1.4) was estimated from the deuterium content of the crystal using this database. Reflectivity was then calculated from the refractive indices by using Equation (7). The optical path schematic of the experiment is shown in Figure 10. Following calculations, Table 5 is obtained. The average absorption coefficient of $97.9 \%$ DKDP crystal is about 0.0052 at $1053 \mathrm{~nm}$, which is less than for the 70\% DKDP and KDP crystals.

\subsection{LIDT of DKDP crystals}

The LIDT is one of the most important properties of DKDP crystals and is a measure of the resistance to laser damage. As-grown DKDP crystal wafers with dimensions of $50 \mathrm{~mm} \times 50 \mathrm{~mm} \times 10 \mathrm{~mm}$ were cut along the $z$-axis direction from the pyramid region of the crystal and polished thoroughly without any coating. These crystal wafers were then measured using an R-on-1 damage testing facility at a wavelength of $1064 \mathrm{~nm}$ with an $8.8 \mathrm{~ns}$ pulse width. The LIDT results are recorded in Figure 11 and listed in Table 6. The LIDT values at $3 \mathrm{~ns}$ and $10 \mathrm{~ns}$ were converted from those at $8.8 \mathrm{~ns}$, which are given in Table 6. From Table 6, the average LIDT of the $97.9 \%$ DKDP crystal used for optical applications is $23.2 \mathrm{~J} \cdot \mathrm{cm}^{-2}$, which exceeds the engineering requirements of higher than $17 \mathrm{~J} \cdot \mathrm{cm}^{-2}$ mandated by Nuclear Physics and Chemistry, China Academy of Engineering Physics. With the introduction of deuterium atoms, the LIDT of DKDP crystal decreased ${ }^{[24]}$. There are many factors that can influence the LIDT of DKDP crystals. To improve the LIDT of highly deuterated DKDP crystals, much work

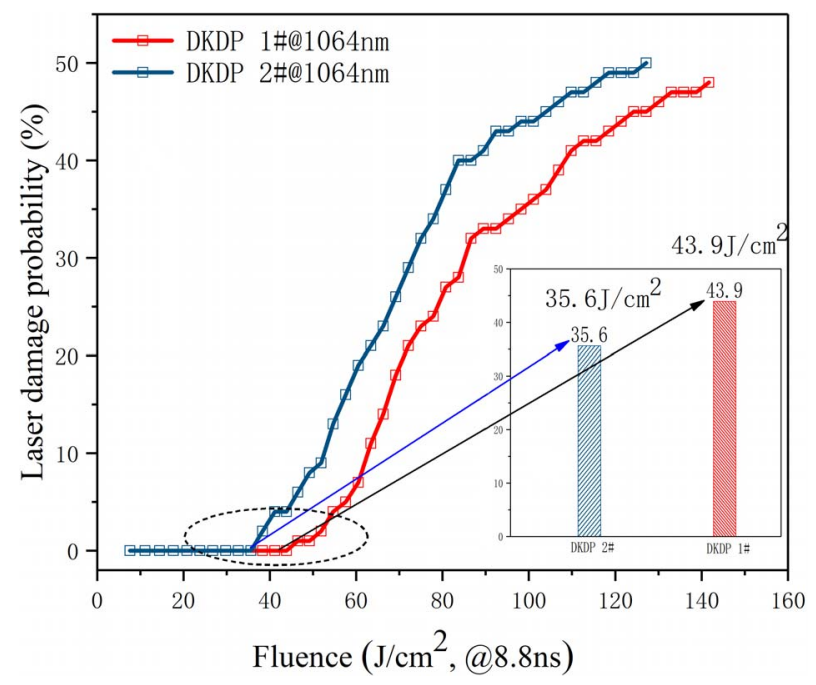

Figure 11. LIDT results. The inset gives the value of LIDT at the inflection point of the curve. The values for samples 1 and 2 are $43.9 \mathrm{~J} \cdot \mathrm{cm}^{-2}$ and $35.6 \mathrm{~J} \cdot \mathrm{cm}^{-2}$, respectively.

Table 6. LIDT results at $8.8 \mathrm{~ns}, 3 \mathrm{~ns}$ and $10 \mathrm{~ns}$.

\begin{tabular}{cccc}
\hline Samples & $\begin{array}{c}\text { LIDT } \\
\text { at } 8.8 \mathrm{~ns}\left(\mathrm{~J} \cdot \mathrm{cm}^{-2}\right)\end{array}$ & $\begin{array}{c}\text { LIDT } \\
\text { at } 3 \mathrm{~ns}\left(\mathrm{~J} \cdot \mathrm{cm}^{-2}\right)\end{array}$ & $\begin{array}{c}\text { LIDT } \\
\text { at } 10 \mathrm{~ns}\left(\mathrm{~J} \cdot \mathrm{cm}^{-2}\right)\end{array}$ \\
\hline$z$-cut-1\# & 43.9 & 25.6 & 46.8 \\
$z$-cut-2\# & 35.6 & 20.8 & 38.0 \\
Average & 39.7 & 23.2 & 42.4 \\
\hline
\end{tabular}

has been carried out by researchers. The LIDT of DKDP with a polymethylsiloxane coating reached approximately $28 \mathrm{~J} \cdot \mathrm{cm}^{-2}(1064 \mathrm{~nm}, 3 \mathrm{~ns})^{[25]}$. Annealing the DKDP samples led to an improvement of the LIDT ${ }^{[23]}$. However, the most important method is improving conditions during the growth process to improve the crystal quality. Further research is in process.

\section{Conclusions}

The properties of a highly deuterated DKDP crystal with sizes of $318 \mathrm{~mm} \times 313 \mathrm{~mm} \times 265 \mathrm{~mm}$ grown by the rapid-growth method in a 500-L crystallizer were studied. A synthesis tank device was designed to synthesize a large volume $(500 \mathrm{~L})$ of high-purity, highly deuterium content growth solution, which effectively avoids the reduction of deuterium ion concentration and hydrogen-deuterium exchange. The deuterium content of the as-grown DKDP crystal was determined by IR spectroscopy and TGA measurements, giving a value of $97.9 \%$. Transmission and absorption coefficient results confirmed that the asgrown DKDP possessed high optical quality in the nearinfrared band. The LIDT of the 97.9\% DKDP crystal was $23.2 \mathrm{~J} \cdot \mathrm{cm}^{-2}(1064 \mathrm{~nm}, 3 \mathrm{~ns}$, R-on-1), which reached the 
engineering requirements for use in optical applications. In summary, highly deuterated DKDP crystals with excellent performance, with over $300 \mathrm{~mm}$ diameter, can be obtained by the same growth method and equipment.

\section{Acknowledgements}

This work is supported by the State High Technology Program for Inertial Confinement Fusion. We thank the Institute of Nuclear Physics and Chemistry, China Academy of Engineering Physics for help with transmittance measurements, and the Shanghai Institute of Optics and Fine Mechanics for help with LIDT measurements.

\section{References}

1. N. P. Zaitseva, J. J. De Yoreo, M. R. Dehaven, R. L. Vital, K. E. Montgomery, M. Richardson, and L. J. Atherton, J. Cryst. Growth 180, 255 (1997).

2. N. Zaitseva and L. Carman, Prog. Cryst. Growth Charact. Mater. 43, 1 (2001).

3. J. J. De Yoreo, A. K. Burnham, and P. K. Whitman, Int. Mater. Rev. 47, 113 (2002).

4. W. Han, F. Wang, L.-D. Zhou, F.-Q. Li, B. Feng, H.-B. Cao, J.-P. Zhao, S. Li, K.-X. Zheng, X.-F. Wei, M.-L. Gong, and W.-G. Zheng, Opt. Express 21, 30481 (2013).

5. S. G. Demos, R. N. Raman, S. T. Yang, R. A. Negres, K. I. Schaffers, and M. A. Henesian, Opt. Express 19, 21050 (2011).

6. W. Han, Y. Xiang, F.-Q. Li, F. Wang, L.-D. Zhou, J.-P. Zhao, B. Feng, K.-X. Zheng, Q.-H. Zhu, X.-F. Wei, W.-G. Zheng, and M.-L. Gong, Appl. Opt. 54, 4167 (2015).

7. A. M. Vakulenko, N. G. Kryukov, Yu A. Matveets, V. I. Panteleev, Yu V. Senatskii, A. I. Fedosimov, and V. T. Yurov, Soviet J. Quantum Electronics 4, 76 (1974).
8. L.-S. Zhang, G.-W. Yu, H.-L. Zhou, L. Li, M.-X. Xu, B.-A. Liu, S.-H. Ji, L.-L. Zhu, F.-F. Liu, and X. Sun, J. Cryst. Growth 401, 190 (2014).

9. P. A. Baisden, L. J. Atherton, R. A. Hawley, T. A. Land, J. A. Menapace, P. E. Miller, M. J. Runkel, M. L. Spaeth, C. J. Stolz, T. I. Suratwala, P. J. Wegner, and L. L. Wong, Fusion Sci. Technol. 69, 295 (2017).

10. S.-L. Wang, Z.-S. Gao, Y.-J. Fu, A.-D. Duan, X. Sun, C.-S. Fang, and X.-Q. Wang, Cryst. Res. Technol. 38, 941 (2003).

11. M.-H. Jiang, C.-S. Fang, X.-L. Yu, M. Wang, T.-H. Zheng, and Z.-S. Gao, J. Cryst. Growth 53, 283 (1981).

12. N. P. Zaitseva, L. N. Rashkovich, and S. V. Bogatyreva, J. Cryst. Growth 148, 276 (1995).

13. L.-S. Zhang, F. Zhang, M.-X. Xu, Z.-P. Wang, and X. Sun, RSC Adv. 5, 74858 (2015).

14. D.-W. Fu, W. Zhang, and R.-G. Xiong, Cryst. Growth Des. 8, 3461 (2008).

15. S. G. Demos, P. DeMange, R. A. Negres, and M. D. Feit, Opt. Express 18, 13788 (2010).

16. M. A. Yakshin, D. W. Kim, Y. S. Kim, Y. Y. Broslavets, O. E. Sidoryuk, and S. Goldstein, Laser Phys. 7, 941 (1997).

17. G. M. Loiacono, J. F. Balascio, and W. Osborne, Appl. Phys. Lett. 24, 455 (1974).

18. T. Huser, C. W. Hollars, W. J. Siekhaus, J. J. De Yoreo, T. I. Suratwala, and T. A. Land, Appl. Spectrosc. 58, 349 (2004).

19. J. Leroudier, J. Zaccaro, J. Debray, P. Segonds, and A. Ibanez, Cryst. Growth Des. 13, 3613 (2013).

20. G.-H. Li, G.-B. Su, X.-X. Zhuang, Z.-D. Li, and Y.-P. He, Opt. Mater. 29, 220 (2006).

21. F.-F. Liu, M.-X. Xu, B.-A. Liu, X.-P. Chen, L. Xie, Y.-H. Xia, C.-W. Wen, L.-S. Zhang, X. Ju, G.-G. Sun, and X. Sun, Opt. Mater. Express 6, 2221 (2016).

22. X.-Y. Xie, H.-J. Qi, B. Wang, H. Wang, D.-Y. Chen, and J.-D. Shao, J. Cryst. Growth 487, 45 (2018).

23. D.-T. Cai, Y.-F. Lian, X.-X. Chai, L.-S. Zhang, L.-M. Yang, and M.-X. Xu, Cryst. Eng. Comm. 20, 7357 (2018).

24. M.-X. Xu, X. Sun, Z.-P. Wang, X.-F. Cheng, S.-T. Sun, L.-L. Ji, Y.-A. Zhao, B.-A. Liu, H. Gao, and X.-G. Xu, Cryst. Res. Technol. 45, 763 (2010).

25. X.-D. Wang, B.-T. Tian, Y.-Y. Niu, G.-M. Wu, B. Zhou, and J. Shen, Rare Metal Mat. Eng. 45, 370 (2016). 